\title{
Establishment and analysis of casting process parameters database
}

\author{
Zhang zhishan, Zhao Hongli
}

Zaozhuang vocational college of science and technology, Shandong Tengzhou 277500

Keywords: casting process; parameter; database

\begin{abstract}
With the development of computer technology, the application of computer technology in foundry industry is becoming more and more widely. This article designs the casting process parameters database through the Delphi technology, and with management and query of the casting process parameters database, you can easily get the technological parameters such as casting shrinkage (scale), machining allowance, stripping slope, the size of minimum cast hole.
\end{abstract}

\section{Introduction}

Casting refers to a processing way that the substance which is at liquid state under the indoor temperature and will soon be cured is poured into the casting mold with particular shape for its solidification. The particularity of casting process is to form through altering the physical state of material, and it is the particularity that caused a lot of trouble for the design of the casting process, which also caused the attention of people. In order to solve this difficult problem, relevant professionals have put forward, before implementation of casting technology solution, we need to type data into the database and in detail analyze the character of the metal. In the past there are a lot of disadvantages in manual analysis, one is the lower efficiency, the second is more wrongs, and the third is difficult to process, thus restricting the process of casting process, reducing the production efficiency. The introduction of computer technology has brought new blood to the casting industry, has injected new vitality, and makes the casting industry get rapid development, then the casting technology database is becoming more and more perfect, so that the level of the casting process is higher and higher.

\section{Establishment of database}

Microsoft SQL Server has two ways to set up a database: (1) using SQL Server Management Studio to set up the database;(2) using the CREATE DATABASE command to create the database. Open the SQL Server Management Studio menu items, in the "connect to Server" dialog box, click on the "ok" button, then will open Microsoft SQL Server database interface. Casting process design parameters (called technological parameters for short) mainly include: the casting shrinkage coefficient (reduced scale), machining allowance, stripping slope, the size of the smallest cast hole. Accurately and suitably selecting process parameters can effectively guarantee the quality of products, increase productivity, and reduce the cost. Otherwise it will cause great wastes.

\subsection{Parameter data of machining allowance}

Machining allowance is divided into ten levels, indicated with A, B, C and other 10 capital English letters.

Table 2.1 Casting machining allowance (RMA) (GB/T6414-1999) (unit: mm)

\begin{tabular}{|c|c|c|c|c|c|c|c|c|c|c|}
\hline \multirow{2}{*}{ Maximum size } & \multicolumn{10}{|c|}{ Required machining allowance } \\
\cline { 2 - 13 } & A & B & C & D & E & F & G & H & J & K \\
\hline$\leq 40$ & 0.1 & 0.1 & 0.2 & 0.3 & 0.4 & 0.5 & 0.5 & 0.7 & 1 & 1.4 \\
\hline$>40-63$ & 0.1 & 0.2 & 0.3 & 0.3 & 0.4 & 0.5 & 0.7 & 1 & 1.4 & 2 \\
\hline$>63-100$ & 0.2 & 0.3 & 0.4 & 0.5 & 0.7 & 1 & 1.4 & 2 & 2.8 & 4 \\
\hline$>100-160$ & 0.3 & 0.4 & 0.5 & 0.8 & 1.1 & 1.5 & 2.2 & 2 & 4 & 6 \\
\hline
\end{tabular}




\begin{tabular}{|c|c|c|c|c|c|c|c|c|c|c|}
\hline$>160-250$ & 0.3 & 0.5 & 0.7 & 1 & 1.4 & 2 & 2.8 & 4 & 5.5 & 8 \\
\hline$>250-400$ & 0.4 & 0.7 & 0.9 & 1.3 & 1.4 & 2.5 & 3.5 & 5 & 7 & 10 \\
\hline$>400-630$ & 0.5 & 0.8 & 1.1 & 1.5 & 2.2 & 3 & 4 & 6 & 9 & 12 \\
\hline$>630-1000$ & 0.6 & 0.9 & 1.2 & 1.8 & 2.5 & 3.5 & 5 & 7 & 10 & 14 \\
\hline$>1000-1600$ & 0.7 & 1 & 1.4 & 2 & 2.8 & 4 & 5.5 & 8 & 11 & 16 \\
\hline$>1600-2500$ & 0.8 & 1.1 & 1.6 & 2.2 & 3.2 & 4.5 & 6 & 9 & 15 & 18 \\
\hline$>2500-4000$ & 0.9 & 1.3 & 1.8 & 2.5 & 3.5 & 5 & 7 & 10 & 15 & 20 \\
\hline$>4000-6300$ & 1 & 1.4 & 2 & 2.8 & 4 & 5.5 & 8 & 11 & 16 & 22 \\
\hline$>6300-10000$ & 1.1 & 1.5 & 2.2 & 3 & 4.5 & 6 & 9 & 12 & 17 & 24 \\
\hline
\end{tabular}

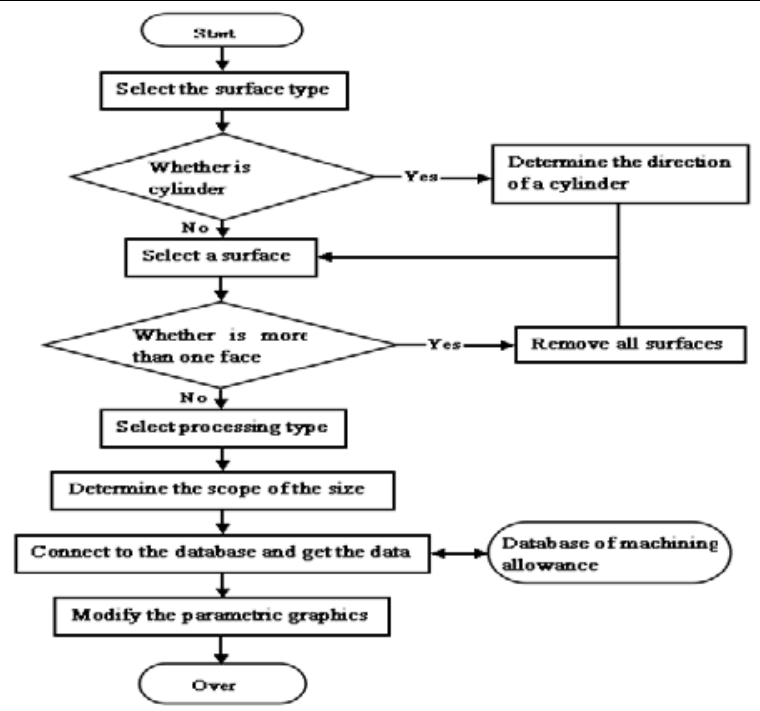

Figure 2.1 The flow chart of machining allowance

\subsection{Minimum cast hole of casting}

During casting, in order to save metal and working hours, the larger hole in the drawing shall be cast out. The holes which are unsuitable to be cast out by reason of small hole or thick casting wall, should directly conduct mechanical processing.

Table 2.2 Size of minimum cast hole of iron castings and nonferrous alloy casting (unit: $\mathrm{mm}$ )

\begin{tabular}{|c|c|c|}
\hline \multirow{2}{*}{ Casting material } & Wall thickness & Minimum-value aperture \\
\hline \multirow{2}{*}{ Cast iron } & $8-10$ & $6-10$ \\
\cline { 2 - 3 } & $20-25$ & $10-15$ \\
\cline { 2 - 3 } & $40-50$ & $15-30$ \\
\cline { 2 - 3 } & $50-100$ & $35-50$ \\
\hline Aluminum alloy, magnesium alloy & - & 20 \\
\hline Copper alloy & - & 25 \\
\hline
\end{tabular}




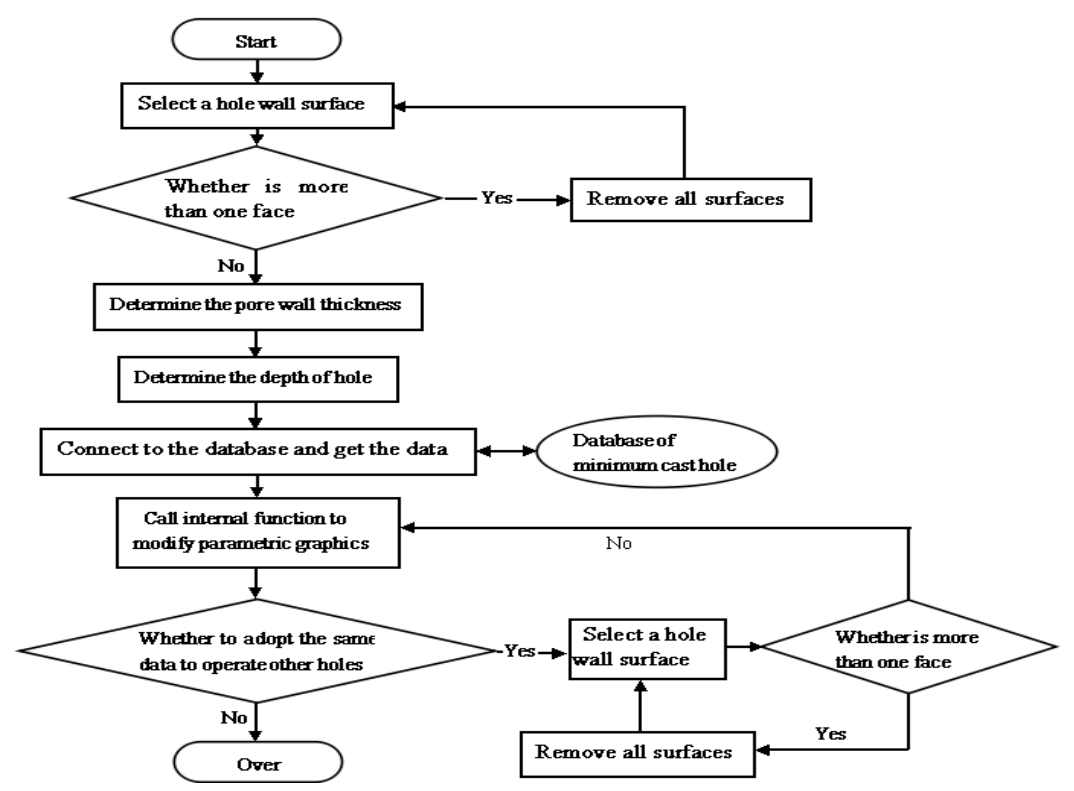

\subsection{Shrinkage}

Figure 2.2 The flow chart of minimum cast hole

Casting shrinkage (also known as casting line shrinkage) refers to the relative linear shrinkage of casting from the linear contraction to the time when the temperature drops to a specific temperature, usually expressed as a percentage:

$$
\varepsilon=\frac{L_{1}-L_{2}}{L_{1}} \times 100 \%
$$

In the type: $\mathrm{L}_{1}$--- shape length; $\mathrm{L}_{2}$--- length of the casting. The actual shrinkage rate of casting size is affected by various factors, such as initial temperature, alloy type, product structure, etc. One of the most main factors is the size of the casting and the degree of the structure complexity. According to the actual situation of the casting, selecting the appropriate line shrinkage or cast magnification is prerequisite to produce castings with higher precision.

Table 3.4 Linear shrinkage rate of steel casting

\begin{tabular}{|c|c|c|}
\hline Shape length $(\mathrm{mm})$ & Resistance of sand mold & Linear shrinkage rate $(\%)$ \\
\hline$\leq 650$ & \multirow{3}{*}{ Free shrinkage } & 2 \\
\hline $650-1850$ & & 1.5 \\
\hline$>1850$ & & 1.25 \\
\hline$\leq 500$ & \multirow{4}{*}{ Hindered contraction } & 2 \\
\hline $500-1200$ & & 1.5 \\
\hline $1201-1700$ & & 1.25 \\
\hline$>1700$ & & 1 \\
\hline \\
\hline \multicolumn{3}{|c|}{$\frac{\downarrow}{\text { Select a casting }}$} \\
\hline \multicolumn{3}{|c|}{$\downarrow$} \\
\hline \multirow{2}{*}{\multicolumn{3}{|c|}{$\downarrow$}} \\
\hline & & \\
\hline$\downarrow$ & \multicolumn{2}{|c|}{ Determine the scope of the size } \\
\hline \multicolumn{3}{|c|}{ Connect to the database $\rightarrow$ Shrinkage dat abase } \\
\hline \multicolumn{3}{|c|}{1} \\
\hline \multicolumn{3}{|c|}{ Modify the parametric graphics } \\
\hline
\end{tabular}

Figure 2.3 The flow chart of shrinkage 


\subsection{Draft Angle module}

In favor of stripping and preventing the destruction of sand mold and sand core, we should set up a certain slope between the core box and the direction of the mold stripping, and the slope is called stripping slope (also called draft angle).Table 2.4 is a steel draft angle data table, in which the mold pattern is divided into two kinds, respectively the metal pattern and wood pattern.

Table 2.4 Draft angle data of steel casting

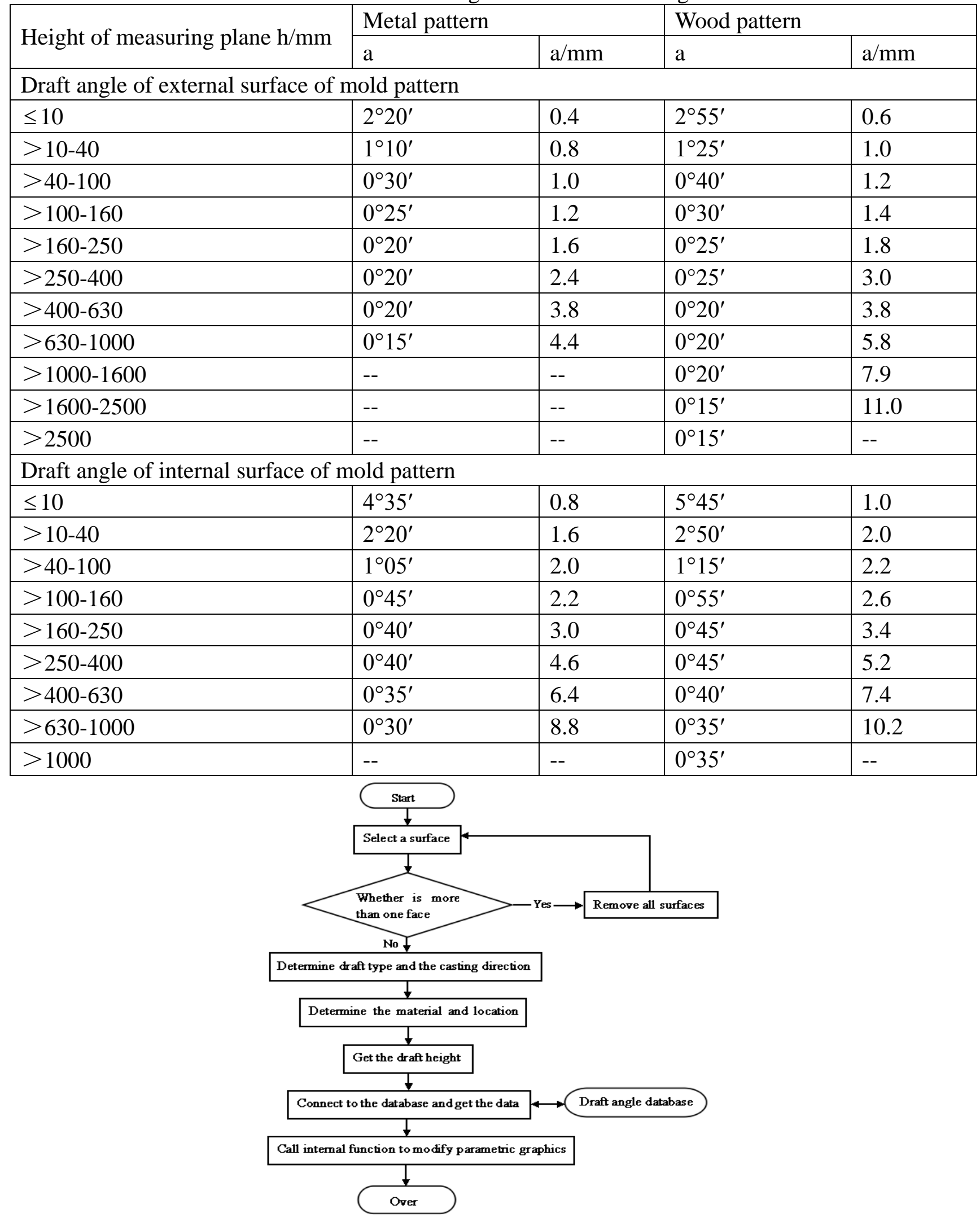

Figure 2.4 The flow chart of draft angle 


\section{Conclusion}

This article combines the computer database technology and casting technology, and introduces the establishment of database and the casting process parameters database, and the design of casting process database is an important tool for future machinery manufacturing production, which not only stores a great deal of practical data related to the casting production, and provides reference standards for the motors of casting processing of casting products.

\section{Reference}

[1] Yang Yi, Jiang yuming. The application and development of computer aided design in casting process [J]. Mechanical, 1999, 26(1): 48-49

[2] Gao shangshu. Computer technology and its application in foundry industry [J]. Journal of casting,1995, (6): 31-37

[3] Gong Xuedan. CAD research and development of steel casting process system based on UG [D]. Wuhan: Huazhong university of science and technology, 2006

[4] Yang jiao. Research and development of casting process database systems [D]. Lanzhou: Lanzhou university of technology, 2010: 45-46 